Universidade de Brasília

Centro de Excelência em Turismo

Gestão da Hospitalidade

\title{
LEVANTAMENTO DAS ESTRATÉGIAS DOS HOTÉIS GOIANIENSES NA CAPTAÇÃO DE EVENTOS E SEUS IMPACTOS NA OCUPAÇÃO
}

Denyze Cordeiro de Almeida

Brasília

2004 
Universidade de Brasília

Centro de Excelência em Turismo

Gestão da Hospitalidade

\title{
LEVANTAMENTO DAS ESTRATÉGIAS DOS HOTÉIS GOIANIENSES NA CAPTAÇÃO DE EVENTOS E SEUS IMPACTOS NA OCUPAÇÃO
}

\begin{abstract}
Monografia apresentada no Curso de Pos Graduação da Universidade de Brasília, como requisito parcial para obtenção do titulo de Pos Graduado em Gestão da Hospitalidade, sob orientação da professora Leonor Câmara.
\end{abstract}

Denyze Cordeiro de Almeida

Brasília 
LEVANTAMENTO DAS ESTRATÉGIAS DOS HOTÉIS GOIANIENSES NA CAPTAÇÃO DE EVENTOS E SEUS IMPACTOS NA OCUPAÇÃO 


\section{SUMÁRIO}

Introdução 6

Capítulo I - Passos Metodológicos 8

1 Tema da Pesquisa $\quad 8$

2 Justificativa 8

3 Problema da Pesquisa 9

4 Objeto da Pesquisa 9

5 Metodologia da Pesquisa $\quad 10$

$\begin{array}{ll}5.1 \text { Classificação da Pesquisa } & 10\end{array}$

Capítulo II - Revisão Bibliográfica 11

1 Turismo de Negócios 11

2 Cidade de Goiânia 12

2.1 Guia turístico, histórico e cultural de Goiás 12

2.2 Atrações turísticas 13

2.3 Principais eventos 15

2.4 Turismo de eventos: o potencial desses negócios para a 16 economia goianiense

$\begin{array}{ll}2.4 .1 \text { Negócios } & 17\end{array}$

3 Conceitos de Estratégias 18

3.1 Estratégias de serviços na hotelaria $\quad 18$

Capítulo III - Pesquisa de Campo 21

1 Análise da Pesquisa de Campo 24 
Capítulo IV - Recomendações e Considerações Finais

Bibliografia

26

Anexos

29

Questionário

31

Gráfico das Perguntas Pesquisadas

32

36 


\section{INTRODUÇÃO}

O setor de serviços e particularmente a indústria de Viagens e Turismo serão consolidados como a maior geradora de emprego e renda em todo o mundo. Nesta indústria o Brasil tem um diferencial de competitividade que o coloca numa posição singular e privilegiada no contexto mundial, devido principalmente ao seu povo e à sua maravilhosa diversidade geográfica.

O avanço no país de grandes redes internacionais, especialmente as européias e as norte-americanas, vêm forçando a industria hoteleira nacional a buscar atualização para acompanhar a concorrência, pois os empreendimentos obsoletos vão ter dificuldades em se manter no mercado.

Para o futuro, apesar de alguns acenos que surgem para o turismo de lazer, como o mega-complexo Costa do Sauípe, na Bahia, o principal foco de investimentos das redes hoteleiras no país, deve ser o turismo de negócios. É para este público que está se voltando o maior número de novos empreendimentos.

O turismo de negócios colabora na divulgação dos atrativos naturais, culturais e sociais da região sede do evento e usa os recursos em momento de baixa estação, ou seja, quando sua procura não é tão significativa por parte dos 
turistas de lazer. Segundo José Vicente Andrade (1997, p. 73-74), Turismo de negócios é:

"O conjunto de atividades de viagem, de hospedagem, de alimentação e de lazer praticado por quem viaja a negócios referentes aos diversos setores da atividade comercial ou industrial ou para conhecer mercados, estabelecer contatos, firmar convênios, treinar novas tecnologias, vender ou comprar bens ou serviços."

Portanto, as redes hoteleiras que não apresentam estratégias eficazes para atender o viajante executivo, já podem começar a se preocuparem. No futuro, estar próximo ao local que é foco do interesse dos executivos em viagem, como torres de escritórios ou centro de convenções, poderá ser um diferencial de destaque para o bom desempenho dos hotéis.

Enfim, a hotelaria nacional aos poucos vem modificando o seu perfil. O mercado hoteleiro cheio de ofertas pede modernidade e eficiência. $E$ a rede hoteleira goianiense dotada de estratégias eficazes para o turismo de negócios tem tudo para sair lucrando neste segmento turístico, pois a posição geográfica da capital goiana, no centro do País, reduz os custos de locomoção dos participantes do evento. Além disso, tem restaurantes de excelente nível e um moderno centro de convenção com amplo espaço, entre outras vantagens competitivas. 


\section{CAPÍTULO I}

\section{PASSOS METODOLÓGICOS}

\section{TEMA DA PESQUISA}

Levantamento das estratégias dos hotéis de Goiânia na captação de eventos e seus impactos na ocupação.

\section{JUSTIFICATIVA}

As empresas e os profissionais necessitam, para o desenvolvimento de suas atividades e negócios, efetuar freqüentes viagens que possibilitem os contatos com pessoas, organismos e empresas, dos quais poderá obter o início, a continuação ou a conclusão de uma atividade ou negócio.

O incremento do turismo de negócios deve ser tratado como vital para o crescimento econômico de qualquer país, pois, além da receita proporcionada ao segmento turístico, o viajante de negócios, uma vez satisfeito nas necessidades cobertas pelo setor turístico, estará disposto a incrementar 
suas atividades no país, trazendo investimentos para a economia e gerando um efeito multiplicador, tanto pelas visitas mais freqüentes que fará, quanto pelas impressões positivas que leva para sua região, tornando um agente de marketing confiável e modificador de opiniões perante sua comunidade. É fundamental que se dê a esse segmento a importância necessária para que ele se incremente.

O foco deve estar no crescimento da oferta de produtos turísticos adequados e na qualidade exigida para satisfazer as necessidades desses turistas especiais, fazendo com que o tempo utilizando nas primeiras atividades a que se propôs com a visita não seja prejudicado por serviços ineficientes e sim complementado com o desfrute prazeroso de todos os serviços que consumir. $O$ turismo de negócio é um grande investimento e fará seu futuro sustentado do mercado turístico.

\section{PROBLEMA DA PESQUISA}

Importância das estratégias na captação de eventos.

\section{OBJETO DA PESQUISA}

Importância das estratégias dos hotéis de Goiânia na captação de eventos, 


\section{METODOLOGIA DA PESQUISA}

Esta pesquisa foi feita em hotéis goianienses classificados pela Associação Brasileira da Industria de Hotéis-ABIH, como sendo Luxo e Superior. A amostra é aleatória simples, foram pesquisados os hotéis que se dispuseram a responder. Do universo de onze hotéis, oito responderam os questionários.

Os instrumentos utilizados para a coleta de dados da pesquisa foram questionários com perguntas abertas, fechadas e de múltipla escolha.

\subsection{Classificação da Pesquisa}

Esta pesquisa do pondo de vista da sua natureza será classificada como sendo uma pesquisa aplicada, pois objetiva gerar conhecimentos para a aplicação prática dirigida a solução de problemas específicos. Do ponto de vista da forma de abordagem do problema, a pesquisa é qualitativa, para se obter um conhecimento mais profundo de casos específicos. Quanto aos objetivos a pesquisa será descritiva, procurando descrever estabelecer relações entre as variáveis. Do ponto de vista dos procedimentos técnicos será de levantamento, consiste na coleta de dados referente às estratégias dos hotéis de Goiânia na captação de eventos e seus impactos na ocupação. 


\section{CAPÍTULO II}

\section{REVISÃO BIBLIOGRÁFICA}

\section{Turismo de negócios}

Graças às campanhas institucionais que vêm sendo feitas no País e no Exterior, o turismo de negócios no Brasil vem crescendo muito nos últimos tempos.

O turismo de negócios é a mais rentável atividade turística em todos os pontos de vista do mundo inteiro. De acordo com a Organização Mundial de Turismo (OMT), o turismo de uma forma geral é o terceiro setor mais lucrativo da economia mundial. A movimentação anual do setor é de aproximadamente US\$ 3,4 trilhões. O turismo de negócios representa $25 \%$ do movimento da indústria turística, cresce a uma média de $30 \%$ ao ano e apresenta uma receita em torno de US\$ 850 bilhões, conforme pesquisa da OMT. 
O turismo de negócios tem várias vantagens em relação ao turismo convencional, o de lazer. A primeira é que o turista de negócios gasta na cidade, aonde vai, até três vezes mais que o de lazer. Enquanto o primeiro gasta, diariamente, $R \$ 250,00$, o segundo desembolsa apenas $R \$ 80,00$. Além desta vantagem, o turista de negócios gera uma cadeia de impostos, pois, como tem de prestar contas à empresa onde trabalha, exige nota fiscal de todos os serviços que utiliza, o que faz aumentar a arrecadação do imposto sobre Circulação de Mercadorias e Serviços (ICMS). Em função dessas vantagens numéricas, muitas cidades, inclusive com vocação e já consagradas no turismo de lazer, como Florianópolis e Joinville, em Santa Catarina, por exemplo, estão investindo na construção de centros de convenções para atrair o turismo, e conseqüentemente, o turista de negócios.

Além de aumentar a arrecadação de tributos, este tipo de turismo também dá uma maior movimentação a vários segmentos da economia. Apesar de os turistas irem às cidades a negócios, encontram tempo para se divertir, gastando em casas noturnas, bares e restaurantes. Eles normalmente nunca voltam para casa sem levar alguma coisa da cidade onde estão, movimentam também o comércio.

\section{Cidade de Goiânia}

Informações retiradas do site da Agetur- Agência de turismo:

\section{1 “Guia Turístico, Histórico e Cultural de Goiás}

Goiânia é uma cidade jovem, moderna e dinâmica. Fundada em 1935 e inicialmente projetada para 40 mil habitantes. Depressa veio desencadear 
o extraordinário processo de expansão de sua área urbana, que superou e muito, as expectativas de seus idealizadores.

Apesar do enorme crescimento verificado desde sua fundação, diversas áreas verdes foram preservadas e implantadas com o carinho de um povo que se preocupa, efetivamente, com o meio ambiente e com sua qualidade de vida.

Goiânia cresce e ocupa novos espaços, sem intimidar-se diante de desafios.

Os frutos do trabalho e dos sonhos de muitos homens e mulheres, essa grande cidade surgiu em meio à vastidão agreste do cerrado, trazendo a marca de uma tradição de pioneirismo e coragem.

Goiânia possui excelente estrutura hoteleira com 7.500 leitos e inúmeros restaurantes, com cardápio internacional e regional nos quais os visitantes se desfrutará de pratos saborosos e de boa qualidade. A vida cultural manifesta-se através de intensa produção artística: peças teatrais, shows, danças, concertos, cinemas e exposições de artes plásticas podem ser apreciadas em diversos espaços culturais.

\subsection{Atrações Turísticas}

- Parque Agropecuário de Goiânia - Onde acontece vários eventos entre eles a maior exposição agropecuária do país. 
- Museus - Encontram-se em nossa cidade vários museus disponíveis aos turistas e população.

- Boates - Em Goiânia se encontram várias boates que abalam as noites goianas em diversos estilos.

- Hotéis Fazendas - Nosso município existem vários hotéis fazendas para o seu descanso e conforto.

- Clubes - Uma das maiores infra-estrutura de lazer e parque aquático do Centro-Oeste.

- Shoppings - Requinte e descontração se misturam entre diversas lojas e paisagens deslumbrantes de suas galerias.

- Bosques e parques - Espaços reservados para a natureza em meio a uma grande cidade com lagos, monumentos e uma vegetação diversificada em sua pequena mata.

- Parque Mutirama - local ideal para todas as idades. Constitui-se de um parque com vários brinquedos para crianças se divertirem como roda gigante, trenzinho, escorregador gigante, casa do terror, montanha russa, mini aviãozinho, carrinho e foguetinhos. É o sonho de todas as crianças. Já para os mais crecidinhos o parque têm planetário e o bosque com uma mini-floresta, lagos, quadras e local para ginástica e cooper. 
- Zoológico - com várias espécies de animais para serem observados, quadras de esportes, parquinho e uma extensa área verde bem arborizada além do lago das Rosas com seus pedalinhos.

- Praças - Existem várias na cidade onde se encontram momentos de lazer em meio à urbanização da cidade.

\subsection{Principais Eventos}

Carnaval - é comemorado em vários clubes da cidade no mais alto estilo.

\section{MAIO}

Exposição Agropecuária - a maior feira de exposição agropecuária do país em negociação e a segunda em público.

\section{JUNHO}

FEIMÁTICA - Feira de informática com novidades e equipamentos de última geração se falando de tecnologia e informática.

\section{AGOSTO}

Cowboy do Asfalto Rodeio Show - uma grande festa no estilo country

FIC Feira da Indústria e Comércio - evento que retrata a realidade da indústria e comércio do estado de Goiás. 
Feira Exponoivas - feira e exposição de artigos para noivas.

\section{SETEMBRO}

Carnagoiânia - um dos maiores eventos do Centro-Oeste que atrai multidões.

\section{OUTUBRO}

Aniversário de Goiânia - com desfiles, orquestras e manifestações populares.

\section{OUTROS EVENTOS}

Cowboy do Asfalto Rodeio Show - uma grande festa no estilo country. FIC Feira da Indústria e Comércio - evento que retrata a realidade da indústria e comércio do estado de Goiás."

\subsection{Turismo de eventos: o potencial desses negócios para a economia goianiense.}

De acordo com uma reportagem do jornal O Popular:

"O turismo de eventos e negócios gera faturamento anual de R\$270 milhões para as empresas de 120 setores econômicos diferentes de Goiânia, Uma das atividades econômicas que mais crescem na capital. São realizados, por ano, 7.100 eventos em Goiânia de todos os tipos, desde chás-de-panela até grandes congressos internacionais, com a participação de 2,2 milhões de pessoas, das quais 435,9 mil de outros Estados e países.

"Nossa pesquisa constatou que são realizados 19 eventos por dia em Goiânia, dos mais diversos tipos. A maioria é de pequeno porte e tem duração 
de até três dias, tanto que $80 \%$ é realizada em hotéis. Mas, a soma de todos causa imenso impacto positivo para a economia goianiense", afirma Celso Orlando.

O setor privado explora cada vez mais esse tipo de turismo em Goiânia,

A infra-estrutura disponível é de boa qualidade e bem dotada de equipamentos, serviços e logística. Uma grande vantagem de Goiânia, em relação às outras capitais do País, é que não existe sérios problemas de trânsito, principalmente de estacionamento.

Rodrigo Borges, diretor da Agência Goiana de Turismo (Agetur), enumera outras vantagens comparativas de Goiânia. "Temos um moderno e amplo centro de convenções, a capacidade hoteleira deve passar dos 10 mil apartamentos entre 2002 e 2003 com os novos investimentos privados no setor, o aeroporto de Goiânia será reformado até a construção de um novo e moderno terminal de passageiros, o custo de realizar eventos na cidade é menor comparado com o de outras capitais, e sem falar na segurança e o no trânsito, em melhor situação frente aos de São Paulo e Rio de Janeiro, por exemplo", diz. Até o fato de Goiânia não ser uma cidade litorânea é destacado por Rodrigo Borges. "Isso eleva à participação das pessoas nos eventos, evitando a dispersão".

\subsubsection{Negócios}

O presidente da Associação Brasileira da Indústria Hoteleira em Goiás (ABIH-GO), Luciano Carneiro, conta que o turismo de eventos passou a ser predominante em Goiânia nos últimos três anos, ultrapassando o turismo de negócios, sendo responsável por investimentos privados em vários setores.

Profissionais do setor de eventos também demonstram maior confiança no crescimento dessa atividade. Marise Leal, vice-presidente da 
Associação Goiana dos Profissionais de Eventos, diz que existem cerca de 500 pessoas na atividade no Estado, 148 delas associadas."

\section{Conceito de Estratégia}

Lodi ( apud Chiavenato, 1997, p.372-373) define estratégia como: "uma mobilização de todos os recursos da empresa no âmbito global visando atingir objetivos a longo prazo, decidida no nível institucional da organização. Quando se constrói uma estratégia, não se pretende tomar hoje decisões sobre o futuro, mas tomar hoje decisões tendo em mente o futuro. A estratégia não pode ser confundida com um de seus planos táticos: estratégias não é só inovação, ou só diversificação ou planejamento financeiro, mas o conjunto disso dirigido a objetivos a longo prazo que se pretende atingir. A estratégia não é um fim em si mesma, mas apenas um meio. Deve ser realizada e reajustada constantemente em função das mudanças. A estratégia não dá certeza, mas apenas a probabilidade com relação ao futuro."

Segundo Aurélio (1986, p726) estratégias é "a arte de aplicar os meios disponíveis com vista à consecução de objetivos específicos. È a arte de explorar condições favoráveis com o fim de alcançar objetivos específicos"

\subsection{Estratégias de serviços na hotelaria}

Para a empresa oferecer um serviço de excelente qualidade, é necessário que ela desenvolva uma estratégia de serviços que, na opinião de W. Davidow e B. Uttal consistem em "segmentar os clientes de acordo com s suas expectativas em relação aos serviços, descobrir quais são exatamente esses 
expectativas e ajustá-las de modo que correspondam a sua capacidade de oferecer serviços". Ou ainda, segundo Albrecht, a estratégia de serviço é "um conceito para conquistar e manter clientes que pode distinguir sua organização das outras opções competitivas na mente do cliente". Para atingir tal objetivo o referido autor disse que é preciso "focalizar as coisas como elas poderiam ser, surgir com uma idéia diferenciada respeito de serviços e valor para o cliente e, a seguir, projetar, desenvolver e entregar o pacote de valor de tal forma que ele possa dar um salto quântico adiante dos concorrentes".

Portanto, se todos os hotéis oferecem aproximadamente a mesma coisa, quem quiser diferenciar deverá oferecer um serviço melhor ou diferente do que os demais, seus concorrentes. Até porque sempre existe uma maneira melhor e diferente de se fazer a mesma coisa. Embora haja homogeneidade, nem por isso deve-se deixar de fazer o esforço para se criar uma estratégia específica. Uma das saídas, para encontrar caminhos, é questionar o próprio cliente, pois, diz o Albrecht "quanto mais intimamente você compreender seus clientes e melhor souber o que estão tentando comprar, maiores serão as chances de identificar o fator critico de posicionamento". E isso vale inclusive para a empresa que atingiu o topo, pois, se já foi uma luta conquistá-lo, a luta ainda maior será manter-se nele. Daí a necessidade da empresa se reposicionar, e isso exige que seus dirigentes revejam "vários aspectos da estratégia competitiva e, possivelmente, até repense a visão, a missão, os valores essenciais e a direção básica para a empresa. Eles devem reexaminar totalmente o pacote de valor para o cliente que trazem ao mercado", enfatiza Albrecht. Ou seja, conclui o referido autor, "é perigoso supor que a maneira pela qual uma industria trabalha hoje é a mesma pela qual ela ira trabalhar amanha".

Através da estratégia de serviços, a empresa está se comprometendo com um pacote de valor diante dos seus clientes. Esse compromisso só pode ser assegurado na medida em que houver um tal comprometimento de todo o quadro funcional.

A empresa precisa oferecer cada vez mais algo de especial para alguém em particular. Este algo especial que ela tem a oferecer aos seus clientes 
é que caracteriza o pacote de valor. O pacote de valor representa aquele elenco de atributos integrantes dos bens e serviços e que são extremamente apreciados pelos clientes. Tais componentes são denominados de críticos. O somatório desses componentes críticos forma o pacote de valor. Diz Albrecht "a empresa tem que apostar as suas fichas no princípio do valor par ao cliente. Desenvolver expandir ou projetar abordagens aos negócios que conquistam e mantêm os clientes pela oferta de valor. A empresa deve saber claramente em que negócio está, quais são suas missões, quais são os seus valores e crenças essenciais e que abordagens estratégicas precisa adotar para ter sucesso através do valor para o cliente. Ela também em que saber como subordinar tecnologia, operações, métodos e estruturas organizacionais às demandas soberanas de uma estratégia empresarial de valor para o cliente". 


\section{CAPÍTULO III}

\section{PESQUISA DE CAMPO}

Esta pesquisa foi feita em todos os hotéis goianienses classificados como Luxo pela HBIH e em cinco, dos oito hotéis, de categoria superior.

Foram aplicados questionários com perguntas abertas, fechadas e de múltipla escolha. Após a coleta dos dados da pesquisa, chegou-se aos seguintes dados.

100\% dos hotéis pesquisados possuem um departamento e departamento específico para eventos.

$37 \%$ dos hotéis pesquisados possuem espaço para eventos com a capacidade 600 pessoas; $13 \%$ com capacidade para 500 pessoas, 300 pessoas e 280 pessoas; $12 \%$ para 200 pessoas e 180 pessoas. Todas em auditório.

Em 49\% dos hotéis pesquisados a taxa ocupacional aumenta em $21 \%$ a $40 \%$ quando há evento no hotel; $25 \%$ dos hotéis aumentam entre $0 \%$ a $20 \%$ e $13 \%$ tem um aumento de $41 \%$ a $60 \%$ e de $81 \%$ a $100 \%$ tem a taxa ocupacional de $13 \%$. 
22\% dos hotéis têm a iniciativa de realizar e divulgar os eventos, já 78\% são solicitado o espaço para eventos e a realização e divulgação são feitas pelo próprio cliente.

87\% das captações de eventos para o hotel são feitas por solicitação do cliente e somente $13 \%$ das captações são feitas por iniciativa do hotel.

75\% dos hotéis são mantenedores do Goiânia Convention \& Visitors Bureau e 25\% dos hotéis pesquisados não são mantenedores. Mantendo o Goiânia Convention \& Visitors Bureau com a taxa de turismo, possibilita a ele meios para:

\footnotetext{
$\checkmark$ Divulgar Goiânia

$\checkmark$ Captar eventos para Goiânia

$\checkmark$ Aumentar a taxa ocupacional dos hotéis de Goiânia

$\checkmark$ Divulgar os Hotéis de Goiânia
}

Seis dos hotéis pesquisados acham que as vantagens de ser um mantenedor do Goiânia Convention \& Visitors Bureau é que possibilita esta instituição captar eventos para a cidade; dois acreditam que divulga Goiânia no Brasil e no Mundo e um acha que divulga os hotéis de Goiânia.

$37 \%$ dos hotéis a taxa ocupacional aumenta de 61\% a $80 \% ; 13 \%$ aumenta de $0 \%$ a 20\%; 25\% dos hotéis aumenta de $41 \%$ a $60 \%$ e de $81 \%$ a $100 \%$ tem a taxa ocupacional de $25 \%$, quando há eventos de grande porte sendo realizados em Goiânia.

Todos os hotéis pesquisados possuem fax, Internet, espaço para convenções e retroprojetor. Dois hotéis não possuem data show; somente um não tinha slides. Cinco hotéis dispõem aos seus hóspedes equipamentos para vídeo conferência. Alguns destes equipamentos são terceirizados. 
100\% dos hotéis pesquisados acham que a localização do hotel facilita na captação de eventos, por localizarem próximo do Centro de Cultura e Convenções de Goiânia.

$62 \%$ não acham que se os hotéis fossem todos localizados em Setores Hoteleiros facilitaria a captação de eventos para Goiânia. Já 38\% acreditam que isso facilitaria e que involuntariamente isto ocorre em Goiânia, porque todos os hotéis de categoria Luxo e grande parte do Superior estão todos localizados no Setor Oeste. E estes hotéis são os que possuem a maior taxa ocupacional.

A estrutura da cidade:

$\checkmark$ Aumentar o número de unidades habitacionais

$\checkmark$ Ter lugares mais atrativos/ pontos turísticos

$\checkmark$ Melhorar a segurança

$\checkmark$ Melhorar o aeroporto, tonto na infra-estrutura quanto nos horários dos vôos

$\checkmark$ Melhorar as vias de acesso a Goiânia

$\checkmark$ Melhorar a sinalização de trânsito

$\checkmark$ Melhorar o serviço de táxi

$\checkmark$ Organizar o comércio informal no centro da cidade

$\checkmark$ Retirar a taxa de turismo

$\checkmark$ Captar mais eventos

A estrutura deste hotel:

$\checkmark$ Aumentar o espaço para convenções

$\checkmark$ Modernizar os equipamentos para convenções

$\checkmark$ Reformar as unidades habitacionais

$\checkmark$ Nada

Dois hotéis pesquisados acham que devem modernizar os equipamentos e ampliar o espaço para convenções. Um hotel precisa reformar as unidades habitacionais e três hotéis acham que não precisa mudar nada em sua estrutura para melhor aproveitar o Turismo de Negócios, 
As estratégias deste hotel:

$\checkmark$ Nada

$100 \%$ dos hotéis acham que devem manter as estratégias para que o turismo de Negócios fosse melhor aproveitado em Goiânia.

Ao marketing utilizado pelo hotel:

$\checkmark$ Melhorar o sistema de informação com as bases de marketing dos outros estados

$\checkmark$ Nada

86\% dos hotéis acham que devem manter o seu marketing, e 14\% precisam melhorar o sistema de informação com as bases de marketing dos outros estados para que o Turismo de Negócios fosse melhor aproveitado em Goiânia,

\section{Análise da pesquisa de campo}

Em meio a acirrada concorrência do segmento de Turismo de Negócios, os hotéis vêem a cada dia aprimorando os seus serviços para satisfazer os seus clientes.

Segundo dados levantados através desta os hotéis goianienses têm entre suas prioridades a melhoria da infra-estrutura das unidades habitacionais, a ampliação do espaço para convenções e a informatização dos sistemas de informação. Também está entre suas prioridades investir em equipamentos com avançada tecnologia para que os seus clientes possam executar os seus negócios de maneira eficaz.

Os hotéis que não se adequarem para atender este turista bastante exigente, que procura conforto, praticidade e agilidade para efetuar seus 
negócios, irão perder mercado para as grandes redes internacionais, que a cada dia vem conquistando espaço no mercado brasileiro.

Através desta pesquisa, podemos notar que a grande maioria dos hotéis goianiense não tem a percepção que sempre há algo a ser melhorado e aprimorado. Mantendo a mesma estrutura e as mesmas estratégias não irão conseguir conquistar espaço neste mercado bastante promissor, para quem tem visão de futuro.

Um hotel, mesmo sendo um mantenedor do Goiânia Convention \& Visitors Bureau, não sabe da importância da taxa de turismo para esta instituição sem fins lucrativos. O Goiânia Convention \& Visitors Bureau trás vários benefícios para Goiânia, captando eventos e divulgando a cidade. Conseguindo, assim, aumentar a taxa ocupacional dos hotéis. Sugeriu, este hotel, que a taxa de turismo repassada para GC \& VB, servindo de suporte financeiro para ela possa ter meios de representar Goiânia, tanto no Brasil, quanto no Mundo, fosse retirada.

É preciso investir no setor para obter resultados futuros positivos do Turismo de Negócios. 


\section{CAPÍTULO IV}

\section{RECOMENDAÇÕES E CONSIDERAÇÕES FINAIS}

Primeiramente, é necessário que o hotel tenha um departamento específico para eventos, para organizar de maneira eficaz a captação de eventos para o hotel ou mesmo oferecer os serviços para que o cliente possa realizar e promover o evento. Para isso ocorrer é de vital importância que o hotel tenha um espaço amplo e bastante flexível para a realização de eventos tanto de grande porte quanto de pequeno porte. Foi constatado, através da pesquisa, que todos os hotéis possuem departamento e espaço específico para eventos, alguns não estão atendendo a demanda, necessitando de ampliação.

Cerca de $78 \%$ dos hotéis pesquisados ficam esperando que os clientes venham até eles para solicitar o espaço para eventos, com esta atitude vão perdendo mercado. O hotel é que deve sempre captar os eventos. Com a hospedagem dos participantes do evento, a taxa ocupacional estará sempre alta, reduzindo o período de sazonalidade. Conforme a pesquisa, 49\% dos hotéis aumenta sua taxa ocupacional, somente, em $21 \%$ a $60 \%$, a ocupação deveria ser de 100\%. Procurar sempre fazer pacotes com melhores preços para os participantes do evento, evitando que unidades habitacionais fiquem vazias no período do evento. 
Ter um programa de pós-venda, para saber se o serviço satisfez o cliente. Fazer relatório de perdas, procurando saber porque tal evento foi realizado em um determinado hotel. Procurando assim, fazer melhoras para que isso não aconteça. Nada é perfeito, tem sempre algo que possa ser melhorado.

Quanto aos recursos, foi constatado que todos os hotéis possuíam retroprojetor, Internet e fax. Mas, há uma deficiência de equipamentos mais modernos e informatizados, que proporcionam uma comunicação simultânea, que facilitam a efetuação dos negócios, como: equipamentos para vídeo conferência, data show e slides.

Estar localizado perto do Centro de Convenções e de grandes centros de pólo de negócios facilita na captação de eventos, devido aos problemas de locomoção nos grandes centros urbanos.

A estrutura da cidade exerce uma grande influência na captação de eventos para a cidade, afetando diretamente a taxa ocupacional dos hotéis. Uma vez que, quando há eventos de grande porte em Goiânia esta taxa chega a 100\%. Para a cidade captar mais eventos de grande porte, é necessário que as unidades habitacionais aumentem, para poder comportar todos os participantes. Em conformidade com a pesquisa de campo, Goiânia precisa melhorar as vias de acesso à cidade, a sinalização de trânsito, o serviço de táxi, a segurança e o aeroporto. Quanto ao aeroporto, tanto na infra-estrutura quanto nos horários dos vôos. Ainda precisa resolver o problema do comercio informal no centro da cidade, pois transmite uma imagem de desorganização para os turistas. $E$ a lembrança que o turista deve levar é de uma cidade bonita e limpa. Para isto é necessário que em Goiânia tenha mais pontos turísticos atrativos e entretenimentos para os turistas.

Para que eventos sejam realizados em Goiânia é necessário que uma empresa represente a cidade e lute para que ela possa, cada vez mais, promover eventos. E este é o principal objetivo do Goiânia Convention \& Visitors Bureau. È de fundamental importância ser um mantenedor desta instituição, fornecendo um suporte financeiro para ele desenvolver suas atividades. Cerca de 
75\% dos hotéis pesquisados são mantenedores desta instituição, proporcionandoos algumas vantagens, como: captação de eventos para Goiânia, divulgação da cidade e dos hotéis, aumentando assim a taxa ocupacional dos hotéis de Goiânia, uma vez que, quando há eventos de grande porte, esta taxa aumenta de $61 \%$ a $80 \%$.

Um fator importante a ressaltar é que os hotéis não conhecem o conceito de estratégia. Querem reformar as unidades habitacionais, aumentar o espaço e modernizar equipamentos para convenções, permanecendo com as mesmas estratégias. Uma vez que, para atingir algum objetivo a longo prazo, é preciso que as estratégias sejam reajustadas em função das mudanças, mobilizando todos os recursos da empresa.

Por fim, os hotéis devem procurar fazer alianças estratégicas entre si. Procurando captar eventos maiores em conjunto, dividindo a hospedagem dos participantes. Repassar a hospedagem, para hotéis parceiros, quando o hotel estiver com lotação máxima. Procurar sempre saber da atuação do governo, em relação ao turismo, solicitar e dar apoio nas questões que possam trazer melhorias para o aproveitamento do turismo de negócios para a cidade de Goiânia. 


\section{BIBLIOGRAFIA}

ALBRECHT, K. Revolução nos serviços: como as empresas podem revolucionar a maneira de tratar os seus clientes. São Paulo: Pioneira, 1992.

-------. A única coisa que importa: trazendo o poder do cliente para dentro da sua empresa. São Paulo: Pioneira, 1993.

Programando o futuro. São Paulo: Makro Books,1993.

, BRADFORD, L. J. Serviço de qualidade - vantagens competitivas. São Paulo: McGraw-Hill,1992.

ANDRADE, José Vicente. Turismo: fundamentos e dimensões. São Paulo: Ática, 1997.

ANDRADE, Renato Brenol. Manual de Eventos. Caxias do Sul: EDUCS, 2001.

ANSARAH, Marília Gomes dos Reis. Turismo- Segmentação de Mercado. São Paulo: Futura,1999.

CASTELLI, Geraldo. Administração Hoteleira. 8. ed. Caxias do Sul: EDUCS,2001. 
CHIAVENATO, Idalberto. Introdução à Teoria Geral da Administração. 5. Ed. São Paulo: Makro Books, 1997.

FERREIRA, Aurélio Buarque de Holanda. Novo Dicionário da Língua Portuguesa. Rio de Janeiro: Nova Fronteira, 1986.

GONÇALVES, Maria Helena Arreto; KRITZ, Sônia. Introdução a Turismo e Hotelaria. Rio de Janeiro: SENAC, 1998.

LAGE, Beatriz H.G., MILONE, Paulo C.. Turismo Teoria e Prática. São Paulo: Atlas, 2000.

NAKENE, Andréa. Técnicas de Organização de Eventos. Rio de Janeiro: Infobook, 2000.

OLIVEIRA, Antônio Pereira. Turismo e Desenvolvimento. São Paulo: Atlas, 2000.

POZA, José María de la Lleida. Estructura Industrial Turística. Barcelona: Oikos-Tau,1993.

RODRIGUES, Jarbas. Turismo de Eventos. Jornal O Popular, Goiânia, 14 out. 2001. Economia. 


\section{ANEXOS}




\section{QUESTIONÁRIO}

Este questionário faz parte do projeto de pesquisa da Universidade de Brasília na área de turismo. Visa desenvolver estratégias para o melhor aproveitamento do Turismo de Negócios pela rede hoteleira goianiense.

Não é necessário a identificação do hotel. O resultado da pesquisa e análise dos dados serão repassados aos hotéis que contribuíram com este trabalho científico.

Obrigada.

1- Há no hotel um departamento específico para eventos?

( )Sim ( )Não

2- Há no hotel espaço para a realização de eventos?

( )Sim ( )Não

3- A capacidade deste espaço é para quantas pessoas?

4- Quando há eventos no hotel a taxa ocupacional aumenta em quantos porcento?

( ) $0 \%$ a $20 \% \quad$ ( )61\% a $80 \%$

( ) $21 \%$ a $40 \% \quad$ ( ) $81 \%$ a $100 \%$

( ) $41 \%$ a $60 \%$ 
5-Como é feita a captação de eventos para o hotel?

( )1-O próprio hotel tem a iniciativa de realizar os eventos e de divulgá-los.

( ) (2-É solicitado ao hotel o espaço para eventos, e a realização e divulgação são feitas pelo próprio cliente.

Qual das duas captações é mais utilizada?

( )1 ( ) 2

6-O hotel é um mantenedor do Goiânia Convention \& Visitors Bureau?

( ) $\operatorname{Sim}($ )Não

7- Quais as vantagens de ser um mantenedor do Goiânia Convention \& Visitors Bureau?

8- Quando eventos de grande porte estão sendo realizados em Goiânia, a taxa ocupacional do hotel aumenta em quantos porcento?

( ) $0 \%$ a $20 \% \quad$ ( )61\% a $80 \%$

( ) $21 \%$ a $40 \% \quad$ ( ) $81 \%$ a $100 \%$

( ) $41 \%$ a $60 \%$

9- Que instalações o hotel dispõem aos seus hospedes que facilite a efetuação de seus negócios?

( ) Fax

( ) Internet

( ) Espaço para convenções

( ) Equipamentos para a execução do evento como: data show

( ) Equipamentos para a execução do evento como: retroprojetor

( ) Equipamentos para a execução do evento como: slides

( )Equipamentos para vídeo conferência 
( )Outros-

10-A localização do hotel facilita na captação de eventos?

( ) Sim ( )Não

11- A empresa acha se os hotéis fossem todos localizados em Setores Hoteleiros facilitaria a captação de eventos para Goiânia?

( ) $\operatorname{Sim}$ ( ) Não

12-O que a empresa acha que deveria ser mudado nos hotéis para que o Turismo de Negócios fosse melhor aproveitado em Goiânia, quanto:

A estrutura da cidade:

A estrutura deste hotel:

As estratégias deste hotel:

Ao marketing utilizado pelo hotel: 